\title{
Negative Experiences and Trust: A Causal Analysis of the Effects of Victimization on Generalized Trust
}

\author{
Paul C. Bauer* \\ Institute of Political Science, University of Bern, Fabrikstrasse 8, CH-3012 Bern, Switzerland \\ *Corresponding author. Email: paul.bauer@ipw.unibe.ch
}

Submitted April 2014; revised November 2014; accepted November 2014

\begin{abstract}
Generalized trust is praised by many researchers as the foundation of functioning social systems. An ongoing debate concerns the question whether and to what extent experiences impact individuals' generalized trust, as measured with the standard trust survey question. So far, reliable empirical evidence regarding the causal effect of experiences on generalized trust is scarce. Studies either do not directly measure the quality of experiences or use designs that are prone to selection bias. In the present study, we investigate a unique panel data set from Switzerland that contains measures of trust and measures of negative experiences, i.e. victimization. We use change score analysis and 'genetic matching' to investigate the causal effect of victimization on generalized trust and find no substantially strong effect that is consistent across panel data waves.
\end{abstract}

\section{Introduction}

Do (negative) experiences influence generalized trust? Generalized trust is defined as 'the belief that "most people can be trusted"' (Uslaner, 2002: p. 21) and may be more generally understood as a standard estimate of the trustworthiness of the average person one encounters (Coleman, 1990: p. 104; Glanville and Paxton, 2007). Besides praising generalized trust as an important ingredient for the functioning of societies, organizations, and political and economic systems (Barber, 1983; Gambetta, 1990; Fukuyama, 1995; Kramer, 1999; Sztompka, 1999; Nooteboom, 2002; Uslaner, 2002; Herreros, 2004; Algan and Cahuc, 2013), researchers debate to this day as to what extent experiences impact generalized trust. A first view is that generalized trust is a stable expectation, a propensity innate or learned in early life but not linked to experience collected throughout one's life (Giddens, 1991;
Wrightsman, 1992; Wilson, 1993; Becker, 1996; Jones, 1996; Uslaner, 2002, 2008). A second view holds that experiences do very well matter for generalized trust (Coleman, 1990; Hardin, 2002; Glanville and Paxton, 2007; Freitag and Traunmüller, 2009; Glanville, Andersson and Paxton, 2013). The empirical evidence regarding this question is mixed. A related debate concerns the costs of crime and more specifically the effects of victimization (Lejeune and Alex, 1973; Fischer, 1984; Brand, Price and Britain, 2000; Entorf and Spengler, 2002; Averdijk, 2010; Braakmann, 2011). It has long been argued that crime hurts societies because experiences in the form of victimization affect individuals' generalized expectations regarding others' trustworthiness and, as a consequence, individuals' inclination to cooperate with others.

We contribute to these two debates in the following way: first, while most trust research uses experience-based 
theoretical arguments (cp. Sturgis, Patulny and Allum, 2009; Glanville, Andersson and Paxton, 2013; Ingen and Bekkers, 2015), few studies (for notable exceptions see Section 2) directly measure the quality of the actual experiences. Mostly studies assume that certain variables such as formal membership or frequent social interactions stand for positive experiences. By focusing on and measuring negative experiences, we provide a direct investigation into the experience-generalized trust relationship. In general, this gap in research is somewhat surprising, as it is commonly claimed that trust is easily destroyed (Baier, 1986; Slovic, 1993). Second, while research on the direct costs of crime is more straightforward (Brand, Price and Britain, 2000; Cohen, 2004), the indirect costs have received far less attention. Evidence on the effects of victimization is largely based on interviews of nonrandomly selected victims and not drawn from comparisons with suitable control groups (cp. Lejeune and Alex, 1973; Fischer, 1984; Averdijk, 2010). Our study adds to these more qualitative studies and contributes to the existing knowledge. Third, ours is the first study to focus on the causal effect of negative experiences on trust. Instead of relying on cross-sectional data (cp. Brehm and Rahn 1997; Salmi, Smolej and Kivivuori, 2007), we rely on several panel waves and use change scores analysis in combination with matching, which is a considerable step forward compared with the earlier research. Our benchmark is an ideal thought experiment that we use to reveal potential threats to the validity of our findings.

Below we start by presenting arguments and evidence for two competing hypotheses. Then we elaborate further on the design of the study. Subsequently, we outline the data and the measures used. Then we present the empirical results before discussing the findings and drawing a conclusion.

\section{Experiences and Generalized Trust: Hypotheses and Evidence}

In developing our hypotheses, we have to bear in mind that we investigate the impact of negative experiencesthat one collects with specific persons-on generalized trust, i.e. a standard estimate or a standard expectation regarding others' behaviour. The idea that individuals adapt their expectations regarding specific others and specific behaviours, such as a neighbour who misbehaves and does not return the borrowed lawnmower, is relatively straightforward. In this case, trust in the neighbour should change following the negative experience. However, the idea of adaptation of expectations is less straightforward with regard to the concept of generalized trust. Accordingly, a first scholarly position holds that experiences do not or do hardly matter for generalized trust. In contrast, it is a stable psychological propensity (Wrightsman, 1992; Becker, 1996; Jones, 1996; Couch and Jones, 1997; Uslaner, 1999, 2002). Uslaner (2002) draws on Erikson (1968: p. 103) and suggests that generalized trust is largely unaffected by experiences with others such as friends and neighbours. Rather, individuals will have high (or low) levels of generalized trust because of their early life experiences, which are largely connected to their parents. ${ }^{1}$ Therefore, generalized trust 'is not experience-based trust' (Uslaner, 2008: p. 291). Besides, as argued above, experiencesnegative or positive-are likely to affect our expectations regarding the specific trustees with whom we collect those experiences but less so our generalized expectations: 'Although some victims reported a general mistrust of people as a consequence of victimization, their mistrust is often focused on groups of people that share demographic characteristics with the specific offenders that committed violence against them, notably immigrants and men' (Averdijk, 2010: p. 128).

Empirical research lends some support to this first position by showing that there is a strong correlation between generalized trust and optimism which, in turn, seems to be a stable trait that is rooted in childhood socialization (Uslaner, 2002) and that generalized trust is rather stable throughout an individual's lifetime (Uslaner, 2002: pp. 162-165). Research investigating the impact of positive experiences (through proxy variables such as voluntary engagement or membership) partly finds no 'causal' relationship with generalized trust. Ingen and Bekkers (2015) analyse five panel studies and find that the presumed positive causal effect of engagement on trust is most probably due to selection. Bekkers (2012) finds no effect of volunteering on trust relying on a 4-year panel study. Finally, Sturgis, Patulny and Allum (2009) find no causal effect of formal or informal connections on trust, relying on the British Household Panel Study. Another study that relies on a panel of immigrants from Turkey, Pakistan, and former Yugoslavia living in Denmark finds no effect of discrimination experiences through teachers on generalized trust (Dinesen, 2010). Above arguments and evidence on the 'irrelevance' of experiences lead to a first research hypothesis: Negative experiences do not have a negative effect on generalized trust (HO).

Other scholars argue that experiences do very well impact generalized trust (Rotter and Stein, 1971; Stack, 1978; Coleman, 1990; Offe, 1999; Hardin, 2002; Burns, Kinder and Rahn, 2003; Yosano and Hayashi, 2005; Glanville and Paxton, 2007), assuming that individuals should generalize from experiences with specific 
others. Especially, with regard to negative experiences, i.e. victimization, scholars have long argued that it might undermine individuals' sense of trust: '[V]ictimization [...] changes one's perceptions of and beliefs about others in society [...] by indicating others as sources of threat or harm rather than sources of support' (Macmillan, 2001: p. 12). There are common psychological responses across victims and varying victimization experiences. These come in the form of a 'shattering of basic assumptions held about themselves and their world' (Janoff-Bulman and Frieze, 1983: p. 1). Even 'minor' victimizations such as burglary or robbery may cause considerable suffering and lead to reactions such as anxiety, fear, and depression (Janoff-Bulman and Frieze, 1983: p. 2). The process of victimization can then be seen as a 'process that involves rebuilding one's assumptive world' (Janoff-Bulman and Frieze, 1983: p. 1). Hence, generalized trusting expectations regarding others' behaviour may change in this process (Lejeune and Alex 1973; Fischer 1984; Bard and Sangrey, 1986; Macmillan 2001; McCann, Sakheim and Abrahamson 1988).

Empirical research also supports this second position. Glanville and Paxton (2007) find that individuals develop a generalized expectation of trustworthiness based on their experiences with different groups of people in localized settings such as the neighbourhood. Similarly, Freitag and Traunmüller (2009: p. 798) find that trust in specific others such as family members can represent a foundation for more generalized trusting expectations. However, both of these studies rely on crosssectional data. Glanville, Andersson and Paxton (2013) find that positive changes in informal social ties enhance trust, relying on two panel waves. Li, Pickles and Savage (2005) investigate the British Household Panel Study and find that embeddedness in informal networks and neighbourhood attachment (not simple membership) are related to higher generalized trust. Moreover, perceptions that one is treated fairly by political authorities seem to matter for generalized trust (Kumlin and Rothstein, 2010; Dinesen, 2012). Quantitative empirical evidence regarding negative experiences is scarce. Research based on the European Social Survey finds that individuals who perceive that they belong to a discriminated group have lower levels of generalized trust (Dinesen and Hooghe, 2010). Brehm and Rahn (1997: p. 1016) rely on pooled cross-sectional data from the General Social Survey and find that burglary victimization undermines generalized trust. Other cross-sectional analyses find effects of victimization experiences on generalized trust among young people in Finland and Denmark (Salmi, Smolej and Kivivuori, 2007; Dinesen,
2012). Generally, cross-sectional data are strongly limited when it comes to causal inference. In addition, there are different studies that investigate the effects of victimization with in-depth interviews. Fischer (1984: p. 169) interviews 50 victims and finds that victimization experiences are similar to 'post traumatic stress disorders' with victims experiencing 'distrust and suspiciousness'. Averdijk (2010: p. 118f) interviews 41 victims and finds that they report a general mistrust of people as a consequence of their victimization, but often this mistrust is focused on groups similar to the offenders. While interviewing 24 mugging victims, Lejeune and Alex (1973) find that assumptions of invulnerability and trust that were present before the event were abandoned thereafter. Although these more qualitative studies lack control groups, they clearly point to the negative reactions of victims. Altogether, arguments and empirical evidence also give weight to a second research hypothesis: Negative experiences do have a negative effect on generalized trust (H1).

\section{Design}

We investigate two competing hypotheses, $\mathrm{H}_{0}$ (no effect) and $\mathrm{H}_{1}$ (negative effect). Causality is generally investigated departing from the counterfactual framework (Rubin 1974; Holland, 1986), and we start by asking what experiment we could ideally carry out to capture the causal effect of interest (Angrist and Pischke, 2008: p. 4). Ideally we would conduct a randomized field experiment to maximize both internal as well as external validity. We would draw a large random sample from our target population (persons living in Switzerland) and measure the level of trust of all sample members by directly accessing their thoughts before and after the treatment. We would recruit homogeneous offenders that randomly treat half of the sample with exactly the same negative factual experience (treatment group) and leave the other half in peace (control group). Random assignment of the treatment would allow for estimating an unbiased (internally valid) causal effect, as it assures that the treatment $D_{i}$ is unrelated to the potential outcomes (Angrist and Pischke, 2008: p. 15). This ideal experiment would have strong external validity, as the sample is representative of a larger Swiss population and the treatment is a real-life experience. Besides, we would control the timing of both, outcome measurement and treatment assignment. Clearly, this ideal experiment can not be realized for ethical and practical reasons. Thus, we have to resort to 'natural' variation of our treatment, i.e. victimization across individuals. The described ideal experiment, however, serves as the benchmark to which 
we can compare our research design to reveal potential validity threats.

In what manner can we use observational data to approximate our ideal experiment (Angrist and Pischke, 2008: p. 7)? In this study, we rely on a panel study design that differs from the ideal in several respects. First, the treatment is not assigned randomly and there might be selection bias. Victimization is not random. Rather, different theories (cp. Wilcox, 2010) such as the lifestyle-exposure theory (Hindelang, Gottfredson and Garofalo, 1978) emphasize that attributes such as gender or age are linked to different patterns of life that increase the risk of being victimized (see also Gottfredson, 1984; Tseloni and Pease, 2004). These individual characteristics are also likely to be related to our outcome variable generalized trust in that there are differences in trust levels between groups of, for instance, age or gender (see e.g. Robinson and Jackson, 2001; Uslaner, 2002: pp. 155-156, 167f). Second, we have a random sample of households rather than individuals and there might be some inter-dependencies between household members. Third, although we have repeated measures of both outcome and treatment just as in the ideal experiment, we do not control the timing of treatment and outcome measurement. The treatment occurs sometime between the yearly panel surveys and potentially the causal effect depends on the timing. Also, we might not have access to all sample members after the treatment (panel attrition). Fourth, in contrast to the benchmark, we do not observe/measure outcome and treatment directly. We have to rely on self-reports by survey respondents, and we have to think how far these self-reports relate to factual reality. In our causal investigation, we have to take all of these points into account.

We deal with the first problem, i.e. selection bias as follows: when assuming parallel trends, that is, the trend in generalized trust in the treatment group in absence of the treatment is equal to the trend in generalized trust in the control group, we can identify the average effect of the treatment on the treated by using change scores as outcome and estimating the parameters of the following model (Allison, 1990; Morgan and Winship, 2007):

$$
\Delta Y_{i}=Y_{i t}-Y_{i t-1}=\beta_{0}+\beta_{1} \cdot D_{i}^{*}+e_{i}
$$

where $\Delta Y_{i}$ is the change in the outcome between first and second measurement, $\beta_{0}$ is an intercept term, namely, the average of the change in the untreated group, and $\beta_{1}$ is the causal effect, the amount added to $\beta_{0}$ when the treatment dummy $D_{i}^{*}$ jumps to one. Finally, $e$ is some error for which we assume normal distribution and mean 0 . This model assures that any stable unobservable confounder cancels itself out of the equation
(Wooldridge, 2010). In addition, we match victims and nonvictims using different covariates to balance out treatment and control group. While matching does not have any advantages regarding selection bias, it has some other advantages (see e.g. Legewie, 2012): After the matching process, only those observations remain that are comparable between treatment and control group, i.e. observations characterized by common support with regard to the covariates (Morgan and Winship, 2007: p. 117). Through this step we include only observations that are 'potentially exposable' to the treatment (Holland, 1986: p. 946). At the same time, matching treatment and control group on various covariates increases justification of the parallel trends assumption, as both groups are more similar. Moreover, matching procedures allow us to evaluate imbalance between treatment and control group and force us to think clearly about potential selection processes. Thus, it makes sense to add the matching step before estimating the change score model. To deal with the other three mentioned validity threats (household dependency, treatment timing, i.e. intensity, and self-reports), we carry out robustness checks that are reported in the empirical section.

\section{Data, Measures and Controls}

The data come from the Swiss Household Panel (SHP) study that follows a random sample of households in Switzerland over time. It started in 1999 with 5,074 households/12,931 household members. In 2004, a second sample of 2,538 households/6,569 household members was added. Annual data collection is carried out by means of computer-assisted telephone interviewing. Using relatively reliable data from a single country is preferable when it comes to causal inference, as several factors that may vary across countries are held constant.

Table 1 gives an overview of panel waves that contain measures of trust and victimization. Starting from 2002, the SHP contains the most widely used trust measure: 'Would you say that most people can be trusted or that you can't be too careful in dealing with people, if 0 means "Can't be too careful" and 10 means "Most people can be trusted"?' This question has received some criticism (Miller and Mitamura, 2003; Nannestad, 2008; Sturgis and Smith, 2010), but it is the only question for which data are available across time both in national survey and in international surveys and has been widely used in recent studies (e.g. Delhey, Newton and Welzel, 2011; Sønderskov, 2011; Traunmüller, 2011; Dinesen, 2013; Mewes, 2014). Refraining from its use would mean to discard data from numerous surveys 
Table 1. Trust and victimization questions across SHP waves

\begin{tabular}{|c|c|c|c|c|c|c|c|c|c|c|c|c|c|c|}
\hline Panel wave & 1999 & 2000 & 2001 & 2002 & 2003 & 2004 & 2005 & 2006 & 2007 & 2008 & 2009 & 2010 & 2011 & 2012 \\
\hline $\begin{array}{l}\text { Social trust }(Y) \\
\text { Insulted or threatened }\left(D_{\text {Threat }}\right) \\
\text { Hit or injured }\left(D_{\text {Injury }}\right) \\
\text { Harassment }\left(D_{\text {Harassment }}\right)\end{array}$ & & & & $\mathbf{\square}$ & $\mathbf{\square}$ & $\begin{array}{l}\mathbf{0} \\
\mathbf{\square} \\
\mathbf{\square}\end{array}$ & $\begin{array}{l}\square \\
\square \\
\square\end{array}$ & $\begin{array}{l}\square \\
\square \\
\square\end{array}$ & $\begin{array}{l}\square \\
\square \\
\square\end{array}$ & $\begin{array}{l}\mathbf{\square} \\
\mathbf{\square} \\
\mathbf{\square}\end{array}$ & $\mathbf{\square}$ & $\mathbf{\square}$ & $\boldsymbol{\square}$ & $\boldsymbol{\square}$ \\
\hline
\end{tabular}

such as the panel survey investigated here. Besides, this question seems to function fairly well within the Swiss context despite cultural and linguistic barriers and strongly correlates with trust in strangers (Freitag and Bauer, 2013). Also, there is further evidence that, especially in Switzerland, respondents associate this question with outgroups (Delhey, Newton and Welzel, 2011). We explicitly assume (as previous researchers have done implicitly) that differences in question interpretation across respondents are not linked to our treatment net of covariates.

There are several questions querying negative experiences from wave 2004 to 2008. Respondents were asked: Have you been insulted or threatened verbally since (month, year)? Have you been hit or injured since (month, year)? Have you been sexually harassed or forced to perform sexual acts since (month, year)? ${ }^{2}$ Therefore, we can draw on considerable amounts of data for the treatments we are interested in. Figure 1 gives an overview of our data and of the whole sample of respondents and shows how many respondents in the respective year have been victimized. It illustrates that the share of individuals suffering graver victimization such as harassment is relatively low, which represents a challenge in terms of estimation.

In general, we assume that selection on stable covariates is the main problem regarding our causal relationship. Certainly, there are attributes that might change between $\mathrm{t}-1$ and $\mathrm{t}$, but they represent a problem only if they are systematically linked to victimization and generalized trust. For instance, one can hardly make a strong argument for a directed impact of changes in civic engagement (Ingen and Bekkers, 2015) or informal social ties (Glanville, Andersson and Paxton, 2013) (see also Section 2) on the probability of being victimized. Thus, we mainly control for the classic sociodemographic variables. We control for gender, age, education, income, and minority status. All of these attributes tend to be linked to certain life patterns and, thus, potentially to victimization (Averdijk, 2010) and may also be linked to generalized trust. Moreover, we control for unemployment status, job loss since the last panel wave, and active membership in organizations. Finally, repeat victimization is increasingly discussed among criminologists (Polvi et al., 1991; Farrell, Phillips and Pease, 1995; Averdijk, 2010). Just as some of the variables above, repeat victimization can be seen as a proxy for other factors. For instance, repeat victims are likely to live in deprived contexts, which might also affect their levels of generalized trust. Table A1 in the appendix presents summary statistics for all variables used in the analysis.

\section{Empirical Results}

Owing to the vast amount of data and the resulting high number of models we analyse (across panel waves and treatments), we chose to display the results graphically. Model summaries can be found in the Appendix. Figure 2 (see Table A2) summarizes the estimates of 12 bivariate regression models, each estimating the naive treatment effect for the respective year. The outcome variable in M1-M12 is trust at time t. The victimization experience has occurred sometime during the year before $t$, but is also queried at $t$. In other words, the effects displayed are simply the differences between the trust averages of those who reported an insult/threat, being hit/injured, or being harassed and those who did not. For all the victimization experiences, the naive estimate of the causal effect is negative and substantially high, considering that generalized trust is measured on an 11-point scale. Logically, uncertainty is higher for those victimization experiences for which we have fewer data points. Unfortunately, scarce data preclude any inference for victims of harassment. Although the point estimate is negative, the $95 \%$ confidence intervals are larger and cross 0 . For this reason, we exclude the harassment treatment in subsequent analyses. Clearly, these naive estimates of the causal effect are likely biased in either negative or positive direction because of selection.

Therefore, in a second step, we use the change score $\Delta Y=Y_{i t}-Y_{i t-1}$ instead of $Y_{i t}$ as the outcome variable. Following $\mathrm{H}_{0}$, we would assume that the naive effect of victimization on generalized trust is due to selection rather than due to a direct effect of victimization on 


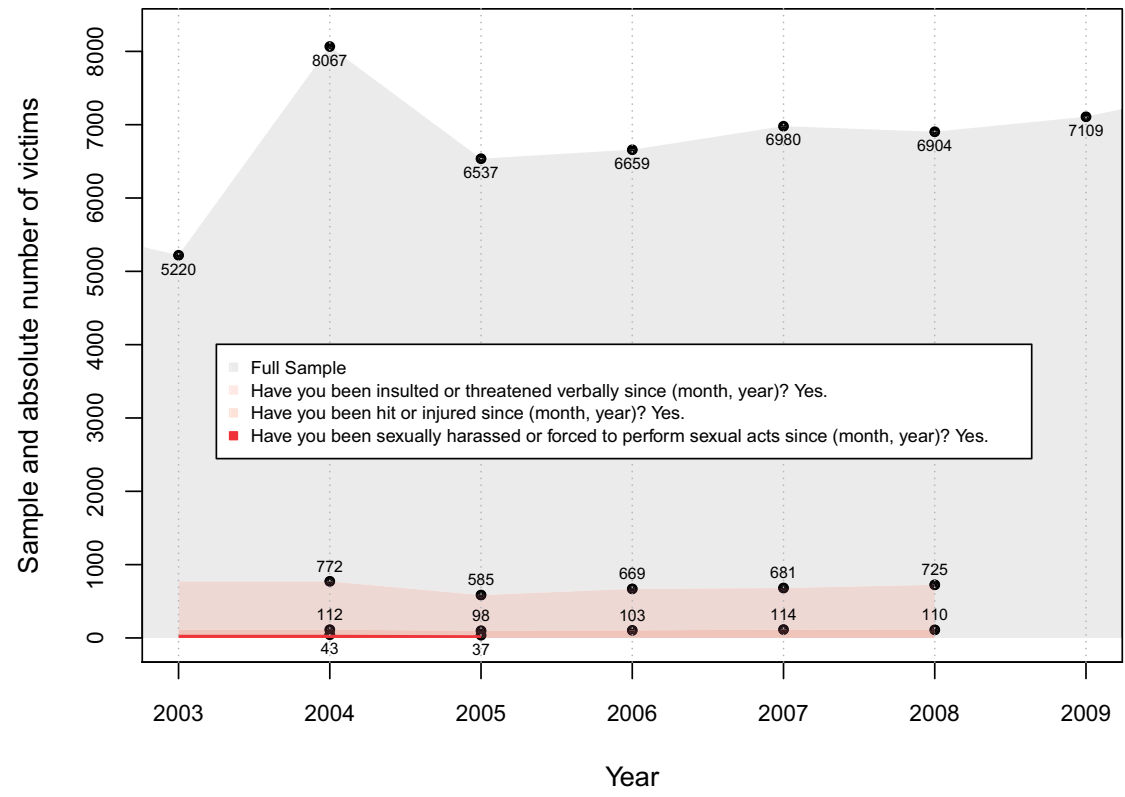

Figure 1. Full sample and absolute number of victims

Note: Graph displays total number of realized individual interviews in the respective years and the number of respondents who answered "yes" to three different victimizations questions querying the occurrence of negative experiences in the previous year. Source: Swiss Household Panel (SHP).

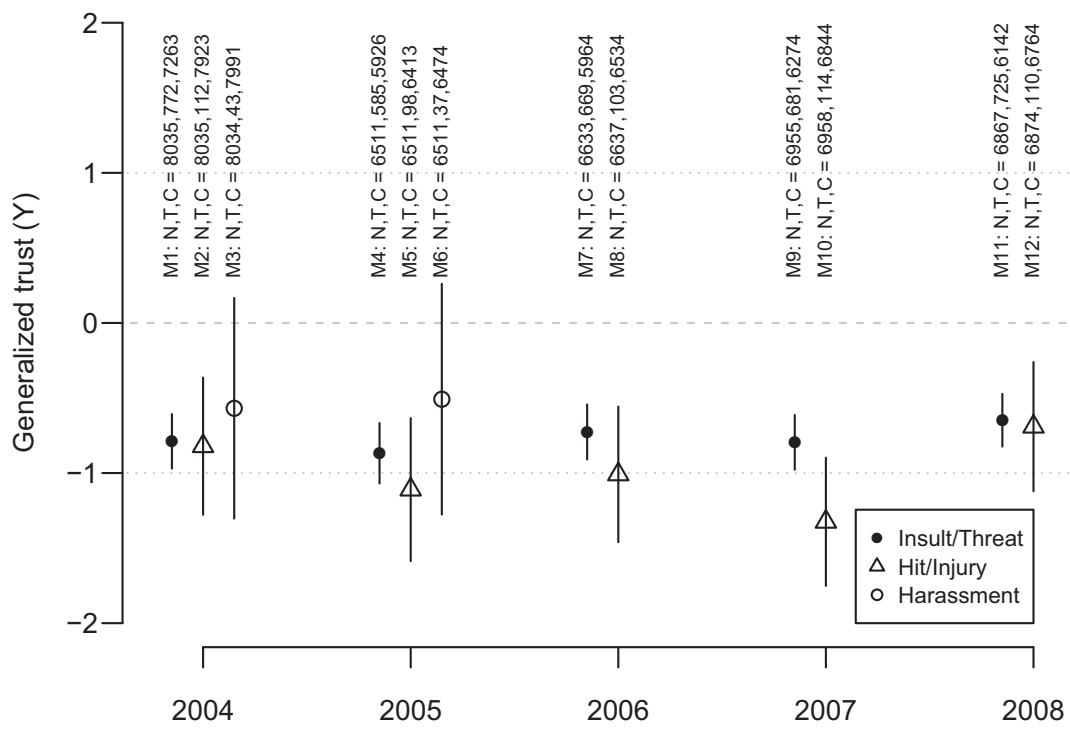

Figure 2. Naive estimates for negative experiences on trust (Table 3)

Note: Symbols are point estimates for 12 bi-variate regression models (OLS); $\mathrm{N}=$ Number observations of which $\mathrm{T}$ are victims and $\mathrm{C}$ are non-victims; Bars are $95 \%$ confidence intervals. Source: Swiss Household Panel (SHP).

generalized trust. Hence, our second analysis should result in lower estimates of the treatment effect. $\mathrm{H}_{1}$, on the other hand, holds that victimization experiences do matter for generalized trust. Figure 3 displays the estimates for the different panel waves (see Table A3). We see that this design changes the picture substantially. The effects of most of the victimization experiences become weaker and 'insignificant' on usual levels. 


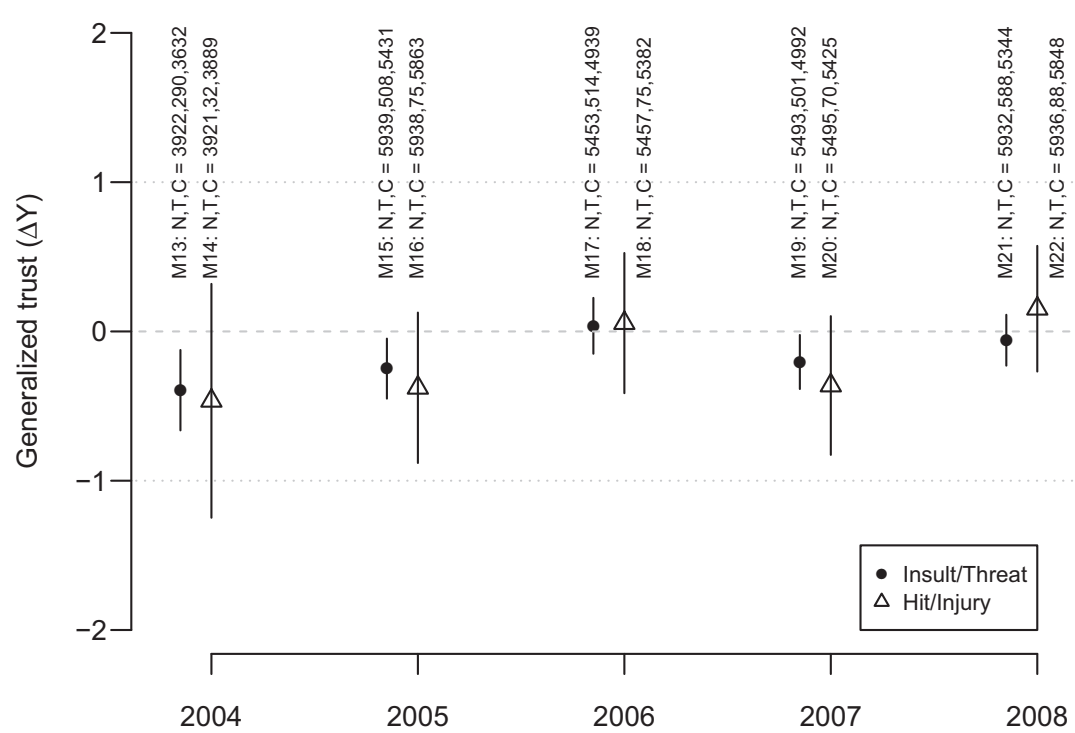

Figure 3. Estimates for victimization on $\Delta$ trust (Table 4)

Note: Points are point estimates for 10 bi-variate regression models (OLS); $\mathrm{N}=$ Number observations of which $\mathrm{T}$ are victims and $\mathrm{C}$ are non-victims; Bars are $95 \%$ confidence intervals. Source: Swiss Household Panel (SHP).

Although, we still find 'significant' effects for threats in 2004, 2005, and 2007 using this more rigorous strategy, these are much smaller in substantial size than before. ${ }^{3}$ In general, these results illustrate how important it is to investigate causal effects across panel data waves. Results obtained for single panel waves may not hold across waves. The presented effects correspond to the difference in trust trends comparing the treatment group with the full control group of untreated, that is, all respondents who did not report to have been victimized at that point in time.

In a third step, we balance treatment and control groups using 'genetic matching' (Sekhon, 2011). We match individuals on gender, age, education, membership, income, victimization (in the previous year), unemployment status, job loss within the respective panel period, and minority status. ${ }^{4}$ The difference to M13M22 is that we now estimate effects using a control group that is comparable regarding these matching variables. Results are displayed in Figure 4 and Table A4. Balance statistics across panel data waves show that there are strong differences between the unbalanced treatment and control groups we used in step two. Before the matching procedure, individuals in the control groups were generally older, better educated, and had higher income. Besides, there were differences in gender composition. After matching, these differences are reduced massively and generally not significant (see Table A5). The results seem to corroborate our findings above. With few exceptions, the point estimates are now close to zero and $95 \%$ confidence intervals mostly cross the zero. In addition, we pooled the matched data sets across years: the weighted averages of the estimates are -0.04 for threat $(\mathrm{SE}=0.06, N=4,616)$ and -0.17 for injury $(\mathrm{SE}=0.16, N=692)$. Using this more rigorous estimation strategy and design, we conclude that we do not find a substantially strong causal effect that is stable across panel data waves.

In a fourth step, we consider further threats to the validity of our conclusions above as exposed by our ideal experiment. First, we measure victimization through self-reports at the end of each period. Factual experiences of differing objective intensity could lurk behind an individual's 'Yes' (Measurement inequivalence). ${ }^{5}$ Also, negative experiences might occur at different points in time between the two panel waves (Timing of the victimization experience). Assumably, effects of victimization are immediate psychological effects, most of which disappear after some months (Denkers and Winkel, 1998). Respondents who answered that they had been victim of a threat or insult between 2004 and 2008 were also asked, 'Are you still affected by this [victimization], if 0 means " not at all" and 10 "a great deal?'. In this additional analysis, we solely focus on threats. ${ }^{6}$ Potentially, individuals who score higher on this scale do so because of one of the above mentioned 


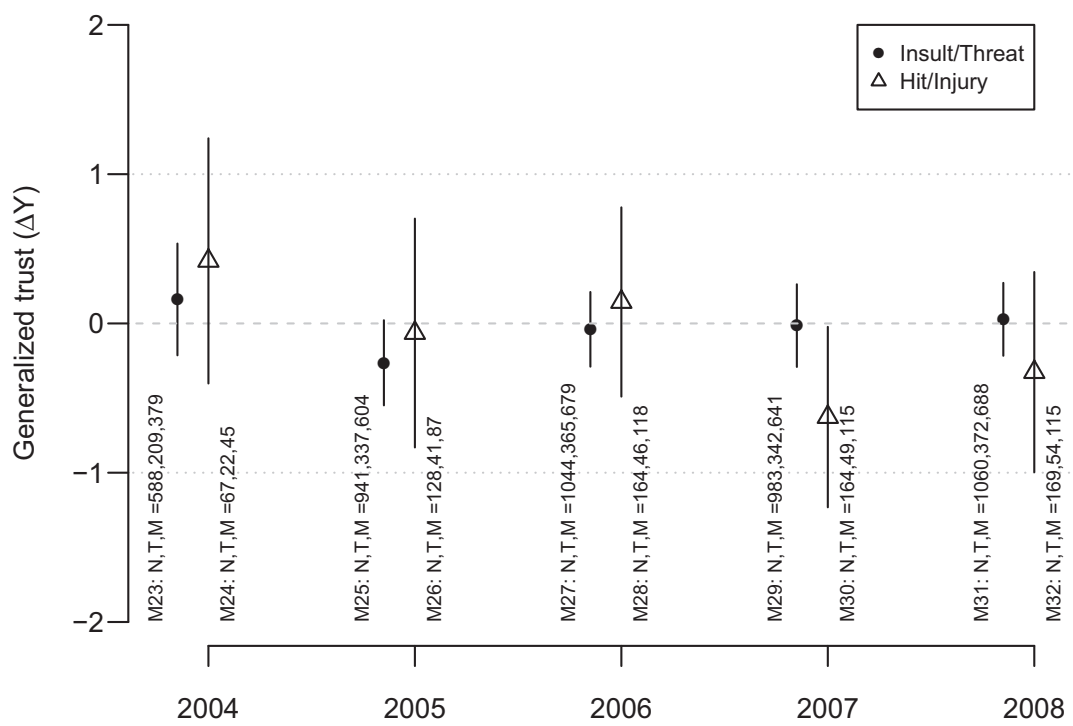

Figure 4. Estimates for victimization on $\Delta$ trust after matching on gender, age, education, membership, income, victimization (previous year), unemployment status, job loss, and minority status (Table 5)

Note: Symbols are point estimates for 10 multivariate regression models (OLS); $\mathrm{N}=$ Number of weighted observations of which $\mathrm{T}$ are victims and $\mathrm{M}$ are matched non-victims; Bars are 95\% confidence intervals. Source: Swiss Household Panel (SHP).

reasons (stronger factual experience, recent timing of the experience), in other words, a causal effect might only be found for intense negative experiences. Accordingly, we reestimated Models M 23, M 25, M 27, M 29, and M 31 (change scores + matching), but now we compare the nonvictims ${ }^{7}$ with those who were insulted/ threatened and score from 7 to 10 on the intensity scale. Figure 5, Table A6, and Table A7 summarize the results. We find that the effects are substantially weak and insignificant across the five waves. Hence, there is no strong counter evidence against our previous conclusions.

Second, when comparing victims with nonvictims we make the assumption that nonvictims are not influenced by victims' negative experiences. However, this assumption may be violated when a nonvictim lives in the same household as a victim. The victim's negative experiences might also affect the trust levels among other household members. If these other household members are part of our control group it biases our estimates. We checked whether there are households with multiple victims. This number is low and thus can be neglected in our view. ${ }^{8}$ Thereafter, we reestimated Models 23-32 with a modified data set that excludes nonvictimized individuals that live together with a victim. The results do not deviate significantly. ${ }^{9}$ Third, we account for the fact that the causal effect might be heterogeneous for different levels of our outcome variable. For instance, individuals with extremely low levels of trust may remain unaffected, i.e. a trust starting value of 0 at $\mathrm{t}-1$ cannot decrease. In general, individuals with extreme values might be less affected by experiences. To test for this possibility, we reestimate Models 23-32, using only respondents with moderate trust levels (3-7) and subsequently only respondents with high trust levels (7-10). All effects in the 20 models we reestimated (for threat and injury) are of negligible substantial size. In other words, our overall conclusions seem to hold in light of these additional robustness checks. ${ }^{10}$

\section{Discussion and Conclusions}

The aim of this article is to contribute to the debate on the relationship between experiences and generalized trust. Using change score analysis combined with matching, we find no causal effect that is substantially strong and consistent across panel data waves. Our findings support the notion that generalized trust as measured with the standard survey question represents a rather stable expectation that is only marginally influenced by victimization experiences. This, somewhat contradicts earlier findings for victimization or proxy variables of positive experiences (Brehm and Rahn, 1997; Li, Pickles and Savage, 2005; Salmi, Smolej and Kivivuori 2007; Glanville, Andersson and Paxton, 2013) and is more in 


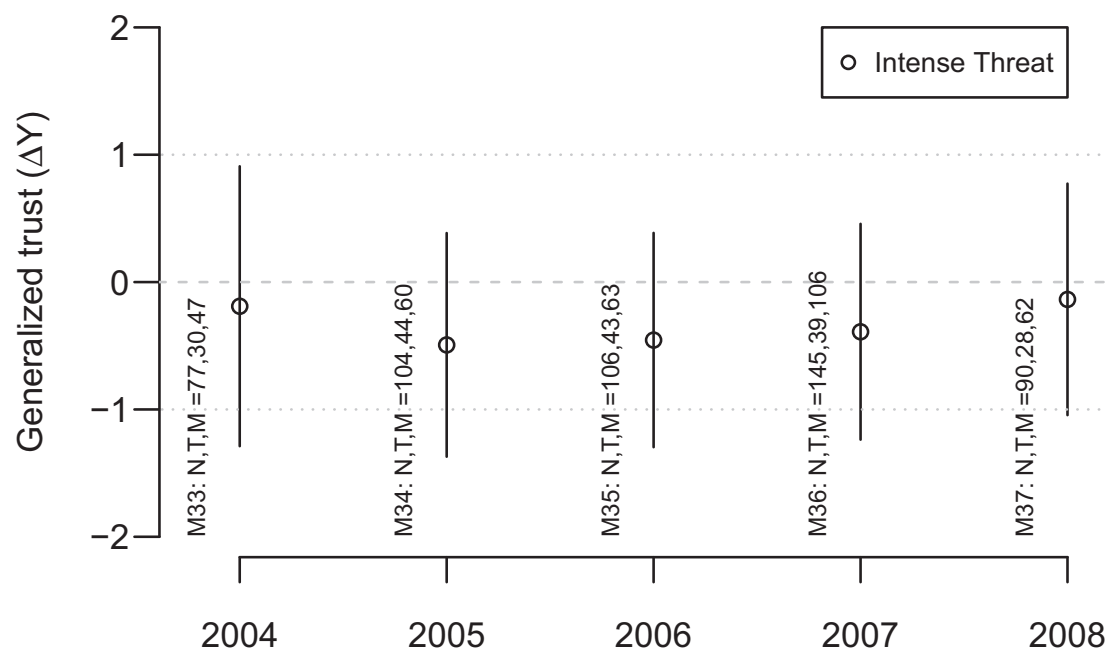

Figure 5. Estimates for victimization of high intensity on $\Delta$ trust after matching on gender, age, education, membership, income, victimization (previous year), unemployment status, job loss, and minority status (Table 7)

Note: Symbols are point estimates for 5 multivariate regression models (OLS); $\mathrm{N}=$ Number of weighted observations of which $\mathrm{T}$ are victims and $\mathrm{M}$ are matched non-victims; Bars are 95\% confidence intervals. Source: Swiss Household Panel (SHP).

line with results that find no effect of experiences (Uslaner, 2002; Ingen and Bekkers, 2015).

Nonetheless, more studies are needed to corroborate our findings, opening multiple avenues of further research. First, our results need to be embedded in the larger context of experience-trust research. Despite our findings, it is still possible that negative experiences do change victims' specific expectations regarding the offender and others that share his or her characteristics (Averdijk, 2010). These more specific trust expectations should matter when it comes to (non)cooperation with these persons or groups. Applying the idea of trust radius (e.g. Delhey, Newton and Welzel, 2011), we would probably find that victims' trust levels remain unchanged for the majority of people, however, trust in persons or groups with offender characteristics decreases. As a consequence, they are excluded from a certain trust radius. To capture these more subtle facets, it is necessary to collect data that include more information on the attributes of the respective offenders and subsequently also data on victims' and nonvictims' more specific trust expectations regarding different trustees. Generally, more specific trust measures would allow for more sophisticated analyses of the experience-trust nexus (Bauer, 2014). Second, in this study, we find almost no evidence for a direct causal effect of victimization experiences. The strong selection bias shows that other factors do matter, in particular, factors that affect both individuals' generalized trust and their probability of victimization. Presumably individuals form their expectations from directly observing others' behaviour and apprehending others' negative experiences. Hence, even without direct victimization, contexts such as a deprived dangerous neighbourhood should matter. In line with this idea, there is evidence that fear of crime is related to generalized trust (Uslaner, 2002: p. 109). More refined longitudinal data on individuals' observations of others' untrustworthy behaviour and on experiences in their social networks and the contexts in which they live is necessary to test these arguments and enhance previous contextual analyses (cp. Ross, Mirowsky and Pribesh, 2001; Marschall and Stolle, 2004; Traunmüller, 2011).

Third, further systematic analyses beyond the single case of Switzerland would be insightful. To our knowledge, the Swiss panel data set used in this study is the only data set that contains appropriate measures and is suited for causal inference. However, it is likely that the impact of victimization on generalized trust depends on the context. Swiss victims can rely on arrangements to deal with the psychological consequences of their experience. Besides, Switzerland possesses a comparably efficient system of justice that punishes offenders. In less developed countries, these conditions might not apply and victimization experiences may be more extreme on average. These speculations need to be investigated empirically. In general, a more thorough understanding of the foundations of trust can only be attained if we are successful in unraveling the complex relationship 
between trusting expectations, childhood experiences, experiences in later life, and the contexts and social networks in which humans are embedded.

\section{Notes}

1 There is also a debate on the impact of genes on trust (Oskarsson et al., 2012; Van Lange, Vinkhuyzen and Posthuma 2014).

2 In wave 2002 and 2003, respondents were asked if they had been attacked or threatened. This question was dropped in 2004 because it confounds verbal and physical victimization.

3 Uncertainty for the 2004 estimates is higher because the sample of respondents in 2003, which we needed to calculate the trust change score, was smaller.

4 In additional models, we controlled for the cumulative history of victimization i.e. the sum of victimizations in previous years. However, this did not change the results (analyses available on request).

5 We had questions for different victimization experiences, however, we could not find reliable evidence that being hit or injured has a stronger effect than e.g. an insult or threat (see Figure 2). The low numbers of respondents for the 'more harsh' victimization experiences preclude any feasible conclusions in this regard (even more so since social desirability may decrease reports of the latter).

6 We assume that individuals who have been hit/ injured or harassed are contained in the group that reports an insult or threat. Besides, we assume that there is less underreporting for this question than for the other two indicators, which is desirable.

7 Control groups are generated from individuals in the same panel wave who did not experience an insult or threat.

8 Across waves 2004-2008, the number of households that contain more than one victim never exceeds 21 out of 1600 to 2005 households.

9 Results are available on request.

10 Another issue is the panel attrition: In general, the SHP is 'not particularly selective with respect to important socio-demographic or -economic variables' (Lipps, 2007: p. 63). Attrition might potentially bias our estimates. If victims drop out between two waves and they are special in that they display higher negative changes in trust than those victims who stay in the survey, we would underestimate the causal effect. Unfortunately, we cannot know whether respondents who dropped out have been victims because they are not present in the second wave when we ask for the victimization experience. However, we carefully assume that this is not the case or otherwise that the numbers of drop out victims with a stronger trend in trust is so small that they do not matter.

\section{Acknowledgements}

I would like to thank Diego Gambetta, Rudi Farys, Fabrizio Bernardi, Markus Freitag, Matthias Fatke, Marlène Gerber and four anonymous reviewers for their helpful comments and suggestions. The R-script is available for replication upon request.

\section{Funding}

This study has been realized using data collected by the Swiss Household Panel (SHP), which is based at the Swiss Centre of Expertise in the Social Sciences FORS and financed by the Swiss National Science Foundation.

\section{References}

Algan, Y. and Cahuc, P. (2013). Trust and growth. Annual Review of Economics, 5, 521-549.

Allison, P. D. (1990). Change scores as dependent variables in regression analysis. Sociological Methodology, 20, 93-114.

Angrist, J. D. and Pischke, J.-S. (2008). Mostly Harmless Econometrics: An Empiricist's Companion. Princeton, NJ: Princeton University Press.

Averdijk, M. D. E. (2010). Individuals'Victimization Patterns Over Time. Free University Amsterdam (PhD thesis).

Baier, A. (1986). Trust and antitrust. Ethics, 96, 231-260.

Barber, B. (1983). The Logic and Limits of Trust. New Brunswick, NJ: Rutgers University Press.

Bard, M. and Sangrey, D. (1986). The Crime Victim's Book. New York, NY: Brunner/Mazel.

Bauer, P. C. (2014). Conceptualizing and measuring trust and trustworthiness. Political Concepts: Committee on Concepts and Methods Working Paper Series, 61, 1-27.

Becker, L. C. (1996). Trust as noncognitive security about motives. Ethics, 107, 43-61.

Bekkers, R. (2012). Trust and volunteering: selection or causation? Evidence from a 4 year panel study. Political Behavior, 34, 225-247.

Braakmann, N. (2011). New evidence on the non-monetary cost of crime based on within-community variation in victimization risks. Working Paper, Newcastle University.

Brand, S., Price, R. and Britain, G. (2000). The Economic and Social Costs of Crime. London: UK Home Office.

Brehm, J. and Rahn, W. (1997). Individual-level evidence for the causes and consequences of social capital. American Journal of Political Science, 41, 999-1023.

Burns, N., Kinder, D. and Rahn, W. (2003). Social trust and democratic politics. Annual Meeting of the Mid-West Political Science Association, Chicago IL. 
Cohen, M. A. (2004). The Costs of Crime and Justice. Oxon: Routledge.

Coleman, J. S. (1990). Foundations of Social Theory. Cambridge: Harvard University Press.

Couch, L. L. and Jones, W. H. (1997). Measuring levels of trust. Journal of Research in Personality, 31, 319-336.

Delhey, J., Newton, K. and Welzel, C. (2011). How general is trust in most people? Solving the radius of trust problem. American Sociological Review, 76, 786-807.

Denkers, A. J. M. and Winkel, F. W. (1998). Crime victims' well-being and fear in a prospective and longitudinal study. International Review of Victimology, 5, 141-162.

Dinesen, P. T. (2010). Upbringing, early experiences of discrimination and social identity: explaining generalised trust among immigrants in Denmark. Scandinavian Political Studies, 33, 93-111.

Dinesen, P. T. (2012). Parental transmission of trust or perceptions of institutional fairness: generalized trust of non-western immigrants in a high-trust society. Comparative Politics, 44, 273-289.

Dinesen, P. T. (2013). Where you come from or where you live? Examining the cultural and institutional explanation of generalized trust using migration as a natural experiment. European Sociological Review, 29, 114-128.

Dinesen, P. T. and Hooghe, M. (2010). When in Rome, do as the Romans do: the acculturation of generalized trust among immigrants in Western Europe. International Migration Review, 44, 697-727.

Entorf, H. and Spengler, H. (2002). Crime in Europe: Causes and Consequences. Heidelberg: Springer.

Erikson, E. H. (1968). Identity: Youth and Crisis. New York, NY: Norton.

Farrell, G., Phillips, C. and Pease, K. (1995). Like taking candywhy does repeat victimization occur. British Journal of Criminology, 35, 384.

Fischer, C. T. (1984). A phenomenological study of being criminally victimized: contributions and constraints of qualitative research. Journal of Social Issues, 40, 161-177.

Freitag, M. and Bauer, P. C. (2013). Testing for measurement equivalence in surveys: dimensions of social trust across cultural contexts. Public Opinion Quarterly, 77(Suppl 1), 24-44.

Freitag, M. and Traunmüller, R. (2009). Spheres of trust: an empirical analysis of the foundations of particularised and generalised trust. European Journal of Political Research, 48, 782-803.

Fukuyama, F. (1995). Trust: The Social Virtues and the Creation of Prosperity. New York: Free Press.

Gambetta, D. (1990). Trust: Making and Breaking Cooperative Relations. Cambridge, MA: Blackwell Publishers.

Giddens, A. (1991). Modernity and Self-identity: Self and Society in the Late Modern Age. Camebridge: Polity Press.

Glanville, J. L., Andersson, M. A. and Paxton, P. (2013). Do social connections create trust? An examination using new longitudinal data. Social Forces, 92, 545-562.

Glanville, J. L. and Paxton, P. (2007). How do we learn to trust? A confirmatory tetrad analysis of the sources of generalized trust. Social Psychology Quarterly, 70, 230-242.
Gottfredson, M. R. (1984). Victims of Crime: The Dimensions of Risk. Home Office Research Study no. 81. London: Home Office Stationery Office.

Hardin, R. (2002). Trust and Trustworthiness. New York: Russell Sage.

Herreros, F. (2004). The Problem of Forming Social Capital. Why Trust? New York: Palgrave Macmillan.

Hindelang, M. J., Gottfredson, M. R. and Garofalo, J. (1978). Victims of Personal Crime: An Empirical Foundation for a Theory of Personal Victimization. Cambridge, MA: Ballinger.

Holland, P. W. (1986). Statistics and causal inference. Journal of the American statistical Association, 81, 945-960.

Ingen, E. and Bekkers, R. (2015). Generalized trust through civic engagement? Evidence from five national panel studies. Political Psychology, 36, 277-294.

Janoff-Bulman, R. and Frieze, I. H. (1983). A theoretical perspective for understanding reactions to victimization. Journal of Social Issues, 39, 1-17.

Jones, K. (1996). Trust as an affective attitude. Ethics, 107, 4-25.

Kramer, R. M. (1999). Trust and distrust in organizations: emerging perspectives, enduring questions. Annual Review of Psychology, 50, 569-598.

Kumlin, S. and Rothstein, B. (2010). Questioning the new liberal dilemma: immigrants, social networks, and institutional fairness. Comparative Politics, 43, 63-80.

Legewie, J. (2012). Die Schätzung von Kausalen Effekten: Überlegungen zu Methoden der Kausalanalyse anhand von Kontexteffekten in der Schule. Kölner Zeitschrift für Soziologie und Sozialpsychologie, 64, 123-153.

Lejeune, R. and Alex, N. (1973). On being mugged: the event and its aftermath. Urban Life and Culture, 2, 259-287.

Li, Y., Pickles, A. and Savage, M. (2005). Social capital and social trust in Britain. European Sociological Review, 21, 109-123.

Lipps, O. (2007). Attrition in the Swiss household panel. Methoden-Daten-Analysen, 1, 45-68.

Macmillan, R. (2001). Violence and the life course: the consequences of victimization for personal and social development. Annual Review of Sociology, 27, 1-22.

Marschall, M. J. and Stolle, D. (2004). Race and the city: neighborhood context and the development of generalized trust. Political Behavior, 26, 125-153.

McCann, I. L., Sakheim, D. K. and Abrahamson, D. J. (1988). Trauma and victimization: a model of psychological adaptation. The Counseling Psychologist, 16, 531-594.

Mewes, J. (2014). Gen(d)eralized trust: women, work, and trust in strangers. European Sociological Review, 30, 373-386.

Miller, A. S. and Mitamura, T. (2003). Are surveys on trust trustworthy? Social Psychology Quarterly, 66, 62-70.

Morgan, S. L. and Winship, C. (2007). Counterfactuals and Causal Inference: Methods and Principles for Social Research. Cambridge, UK: Cambridge University Press.

Nannestad, P. (2008). What have we learned about generalized trust, if anything? Annual Review of Political Science, 11, 413-436. 
Nooteboom, B. (2002). Trust: Forms, Foundations, Functions, Failures and Figures. Cheltenham: Edwar Elgar.

Offe, C. (1999). How can we trust our fellow citizens? In M. E., Warren (Ed.) Democracy and Trust. Cambridge: Cambridge University Press, pp. 42-87.

Oskarsson, S., Dawes, C., Johannesson, M. and Magnusson, P.K.E. (2012). The genetic origins of the relationship between psychological traits and social trust. Twin Research and Human Genetics, 15, 21-33.

Polvi, N., Looman, T., Humphries, C. and Pease, K. (1991). The time course of repeat burglary victimization. British Journal of Criminology, 31, 411-414.

Robinson, R. V. and Jackson, E. F. (2001). Is trust in others declining in America? An age-period-cohort analysis. Social Science Research, 30, 117-145.

Ross, C. E., Mirowsky, J. and Pribesh, S. (2001). Powerlessness and the amplification of threat: neighborhood disadvantage, disorder, and mistrust. American Sociological Review, 66, 568-591.

Rotter, J. B. and Stein, D. K. (1971). Public attitudes toward the trustworthiness, competence, and altruism of twenty selected occupations. Journal of Applied Social Psychology, 1, 334-343.

Rubin, D. B. (1974). Estimating causal effects of treatments in randomized and nonrandomized studies. Journal of Educational Psychology, 66, 688.

Salmi, V., Smolej, M. and Kivivuori, J. (2007). Crime victimization, exposure to crime news and social trust among adolescents. Young, 15, 255-272.

Sekhon, J. S. (2011). Multivariate and propensity score matching software with automated balance optimization: the matching package for R. Journal of Statistical Software, 42, $1-52$.

Slovic, P. (1993). Perceived risk, trust, and democracy. Risk Analysis, 13, 675-682.

Sønderskov, K. M. (2011). Does generalized social trust lead to associational membership? Unravelling a bowl of well-tossed spaghetti. European Sociological Review, 27, 419-434.
Stack, L. C. (1978). Trust. In London, H. and Exner, J. E. Jr (Eds.), Dimensions of Personality. New York: John Wiley \& Sons. pp. 561-599.

Sturgis, P., Patulny, R. and Allum, N. (2009). Re-evaluating the individual level causes of trust: a panel data analysis. Working Paper, University of Southampton.

Sturgis, P. and Smith, P. (2010). Assessing the validity of generalized trust questions: what kind of trust are we measuring? International Journal of Public Opinion Research, 22, 74-92.

Sztompka, P. (1999). Trust: A Sociological Theory. Cambridge, UK: Cambridge University Press.

Traunmüller, R. (2011). Moral communities? Religion as a source of social trust in a multilevel analysis of 97 German regions. European Sociological Review, 27, 346-363.

Tseloni, A. and Pease, K. (2004). Repeat personal victimization random effects, event dependence and unexplained heterogeneity. British Journal of Criminology, 44, 931-945.

Uslaner, E. M. (1999). Democracy and trust. In M., Warren (Ed.), Democracy and Social Capital. Cambridge: Cambridge University Press, pp. 121-150.

Uslaner, E. M. (2002). The Moral Foundations of Trust. Cambridge, UK: Cambridge University Press.

Uslaner, E. M. (2008). The foundations of trust: macro and micro. Cambridge Journal of Economics, 32, 289-294.

Van Lange, P. A. M., Vinkhuyzen, A. A. E. and Posthuma, D. (2014). Genetic influences are virtually absent for trust. PloS One, 9, e93880.

Wilcox, P. (2010). Theories of victimization. In B. S., Fisher and S. P., Lab (Eds.), Encyclopedia of Victimology and Crime Prevention. Thousand Oaks, CA: SAGE Publications, pp. 978-986.

Wilson, J. Q. (1993). The Moral Sense. New York: Free Press.

Wooldridge, J. M. (2010). Econometric Analysis of Cross Section and Panel Data. Cambridge, MA: MIT Press.

Wrightsman, L. S. (1992). Assumptions About Human Nature: Implications for Researchers and Practitioners. Newbury Park, CA: Sage.

Yosano, A. and Hayashi, N. (2005). Social stratification, internediary groups and creation of trustfulness. Sociological Theory and Methods, 20, 27-44. 
Appendix 1

Table A1. Summary statistics

\begin{tabular}{|c|c|c|c|c|c|c|c|c|}
\hline Variable & Number & $N$ & Mean & SD & Median & Minimum & Maximum & Range \\
\hline Trust 2003 & 1 & 4,466 & 5.76 & 2.39 & 6 & 0 & 10 & 10 \\
\hline Trust 2004 & 2 & 8,035 & 5.66 & 2.45 & 6 & 0 & 10 & 10 \\
\hline Trust 2005 & 3 & 6,430 & 6.07 & 2.38 & 7 & 0 & 10 & 10 \\
\hline Trust 2006 & 4 & 6,383 & 6.15 & 2.29 & 7 & 0 & 10 & 10 \\
\hline Trust 2007 & 5 & 5,949 & 6.23 & 2.26 & 7 & 0 & 10 & 10 \\
\hline Trust 2008 & 6 & 5,793 & 6.26 & 2.27 & 7 & 0 & 10 & 10 \\
\hline Trust 2003-2004 & 7 & 3,922 & 0.27 & 2.25 & 0 & -10 & 10 & 20 \\
\hline Trust 2004-2005 & 8 & 5,942 & 0.29 & 2.21 & 0 & -10 & 10 & 20 \\
\hline Trust 2005-2006 & 9 & 5,403 & 0.06 & 2.06 & 0 & -10 & 10 & 20 \\
\hline Trust 2006-2007 & 10 & 5,321 & 0.01 & 1.97 & 0 & -10 & 10 & 20 \\
\hline Trust 2007-2008 & 11 & 5,149 & 0.02 & 1.94 & 0 & -10 & 10 & 20 \\
\hline Threat 2004 & 12 & 8,115 & 0.10 & 0.29 & 0 & 0 & 1 & 1 \\
\hline Threat 2005 & 13 & 6,461 & 0.09 & 0.28 & 0 & 0 & 1 & 1 \\
\hline Threat 2006 & 14 & 6,407 & 0.10 & 0.30 & 0 & 0 & 1 & 1 \\
\hline Threat 2007 & 15 & 5,970 & 0.09 & 0.29 & 0 & 0 & 1 & 1 \\
\hline Threat 2008 & 16 & 5,817 & 0.10 & 0.30 & 0 & 0 & 1 & 1 \\
\hline Intense threat 2004 & 17 & 7,471 & 0.02 & 0.13 & 0 & 0 & 1 & 1 \\
\hline Intense threat 2005 & 18 & 5,980 & 0.01 & 0.12 & 0 & 0 & 1 & 1 \\
\hline Intense threat 2006 & 19 & 5,880 & 0.02 & 0.12 & 0 & 0 & 1 & 1 \\
\hline Intense threat 2007 & 20 & 5,472 & 0.01 & 0.11 & 0 & 0 & 1 & 1 \\
\hline Intense threat 2008 & 21 & 5,300 & 0.01 & 0.10 & 0 & 0 & 1 & 1 \\
\hline Injury 2004 & 22 & 8,115 & 0.01 & 0.12 & 0 & 0 & 1 & 1 \\
\hline Injury 2005 & 23 & 6,462 & 0.01 & 0.12 & 0 & 0 & 1 & 1 \\
\hline Injury 2006 & 24 & 6,412 & 0.02 & 0.12 & 0 & 0 & 1 & 1 \\
\hline Injury 2007 & 25 & 5,973 & 0.01 & 0.12 & 0 & 0 & 1 & 1 \\
\hline Injury 2008 & 26 & 5,822 & 0.01 & 0.12 & 0 & 0 & 1 & 1 \\
\hline Harassment 2004 & 27 & 8,114 & 0.01 & 0.07 & 0 & 0 & 1 & 1 \\
\hline Harassment 2005 & 28 & 6,462 & 0.01 & 0.07 & 0 & 0 & 1 & 1 \\
\hline 29 & & 12,248 & 0.49 & 0.50 & 0 & 0 & 1 & 1 \\
\hline $\operatorname{Age}^{a}$ & 30 & 12,248 & 42.17 & 18.80 & 42 & 11 & 95 & 84 \\
\hline Education 2003 & 31 & 5,913 & 4.45 & 3.05 & 4 & 0 & 10 & 10 \\
\hline Education 2004 & 32 & 12,094 & 4.48 & 3.03 & 4 & 0 & 10 & 10 \\
\hline Education 2005 & 33 & 9,342 & 4.62 & 3.05 & 4 & 0 & 10 & 10 \\
\hline Education 2006 & 34 & 8,619 & 4.70 & 3.06 & 4 & 0 & 10 & 10 \\
\hline Education 2007 & 35 & 7,719 & 4.83 & 3.06 & 4 & 0 & 10 & 10 \\
\hline Member 2003 & 36 & 12,248 & 0.21 & 0.40 & 0 & 0 & 1 & 1 \\
\hline Member 2004 & 37 & 12,248 & 0.35 & 0.48 & 0 & 0 & 1 & 1 \\
\hline Member 2005 & 38 & 12,248 & 0.29 & 0.46 & 0 & 0 & 1 & 1 \\
\hline Member 2006 & 39 & 12,248 & 0.28 & 0.45 & 0 & 0 & 1 & 1 \\
\hline Member 2007 & 40 & 12,248 & 0.26 & 0.44 & 0 & 0 & 1 & 1 \\
\hline Income 2003 & 41 & 2,934 & 1.43 & 1.13 & 1 & 0 & 3 & 3 \\
\hline Income 2004 & 42 & 5,188 & 1.41 & 1.13 & 1 & 0 & 3 & 3 \\
\hline Income 2005 & 43 & 4,297 & 1.42 & 1.14 & 1 & 0 & 3 & 3 \\
\hline Income 2006 & 44 & 4,225 & 1.41 & 1.15 & 1 & 0 & 3 & 3 \\
\hline Income 2007 & 45 & 4,007 & 1.41 & 1.17 & 1 & 0 & 3 & 3 \\
\hline Victim 2003 & 46 & 12,248 & 0.01 & 0.10 & 0 & 0 & 1 & 1 \\
\hline Victim 2004 & 47 & 12,248 & 0.07 & 0.25 & 0 & 0 & 1 & 1 \\
\hline Victim 2005 & 48 & 12,248 & 0.05 & 0.22 & 0 & 0 & 1 & 1 \\
\hline
\end{tabular}


Table A1. Continued

\begin{tabular}{lccccccc}
\hline Variable & Number & \multicolumn{1}{c}{$\boldsymbol{N}$} & Mean & SD & Median & Minimum & Maximum \\
\hline Victim 2006 & 49 & 12,248 & 0.05 & 0.22 & 0 & 0 & 1 \\
Victim 2007 & 50 & 12,248 & 0.05 & 0.21 & 0 & 0 & 1 \\
Unemployed 2003 & 51 & 4,478 & 0.02 & 0.14 & 0 & 0 & 1 \\
Unemployed 2004 & 52 & 8,109 & 0.02 & 0.14 & 0 & 0 & 1 \\
Unemployed 2005 & 53 & 6,461 & 0.02 & 0.13 & 0 & 0 & 1 \\
Unemployed 2006 & 54 & 6,408 & 0.02 & 0.14 & 0 & 0 & 1 \\
Unemployed 2007 & 55 & 5,973 & 0.01 & 0.12 & 0 & 0 & 1 \\
Job loss 2003-2004 & 56 & 3,945 & 0.01 & 0.09 & 0 & 0 & 1 \\
Job loss 2004-2005 & 57 & 5,999 & 0.01 & 0.10 & 0 & 0 & 1 \\
Job loss 2005-2006 & 58 & 5,439 & 0.01 & 0.09 & 0 & 0 & 1 \\
Job loss 2006-2007 & 59 & 5,360 & 0.01 & 0.07 & 0 & 0 & 1 \\
Job loss 2007-2008 & 60 & 5,183 & 0.01 & 0.08 & 0 & 0 & 1 \\
Minority 2003 & 61 & 6,018 & 0.01 & 0.09 & 0 & 0 & 1 \\
Minority 2004 & 62 & 12,234 & 0.01 & 0.11 & 0 & 0 & 1 \\
Minority 2005 & 63 & 9,405 & 0.01 & 0.10 & 0 & 0 & 1 \\
Minority 2006 & 64 & 8,658 & 0.01 & 0.10 & 0 & 0 & 1 \\
Minority 2007 & 65 & 7,731 & 0.01 & 0.09 & 0 & 0 & 1 \\
\hline
\end{tabular}

Note: ${ }^{a}$ Age and gender variables taken from 2004 wave that includes the 1999 sample and the additional 2004 sample from the SHP. Source: Swiss Household Panel (SHP). 


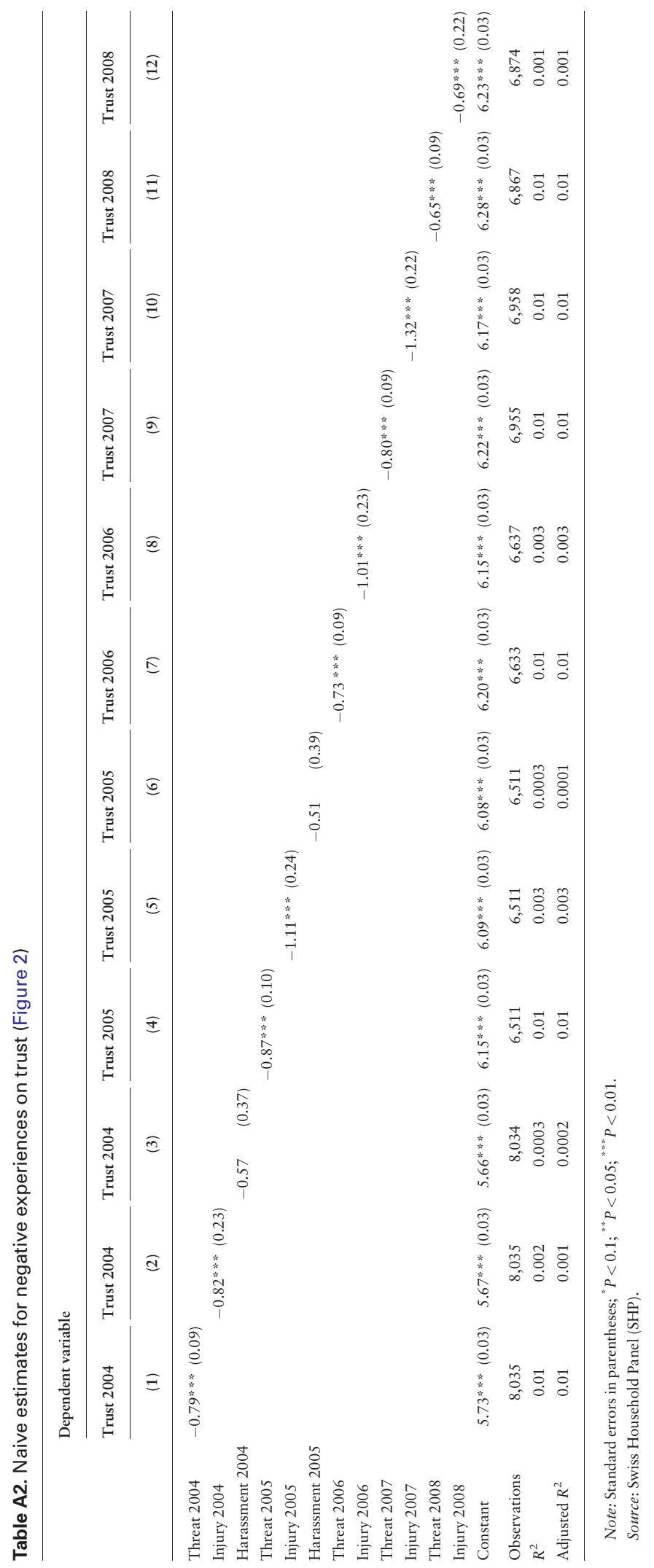




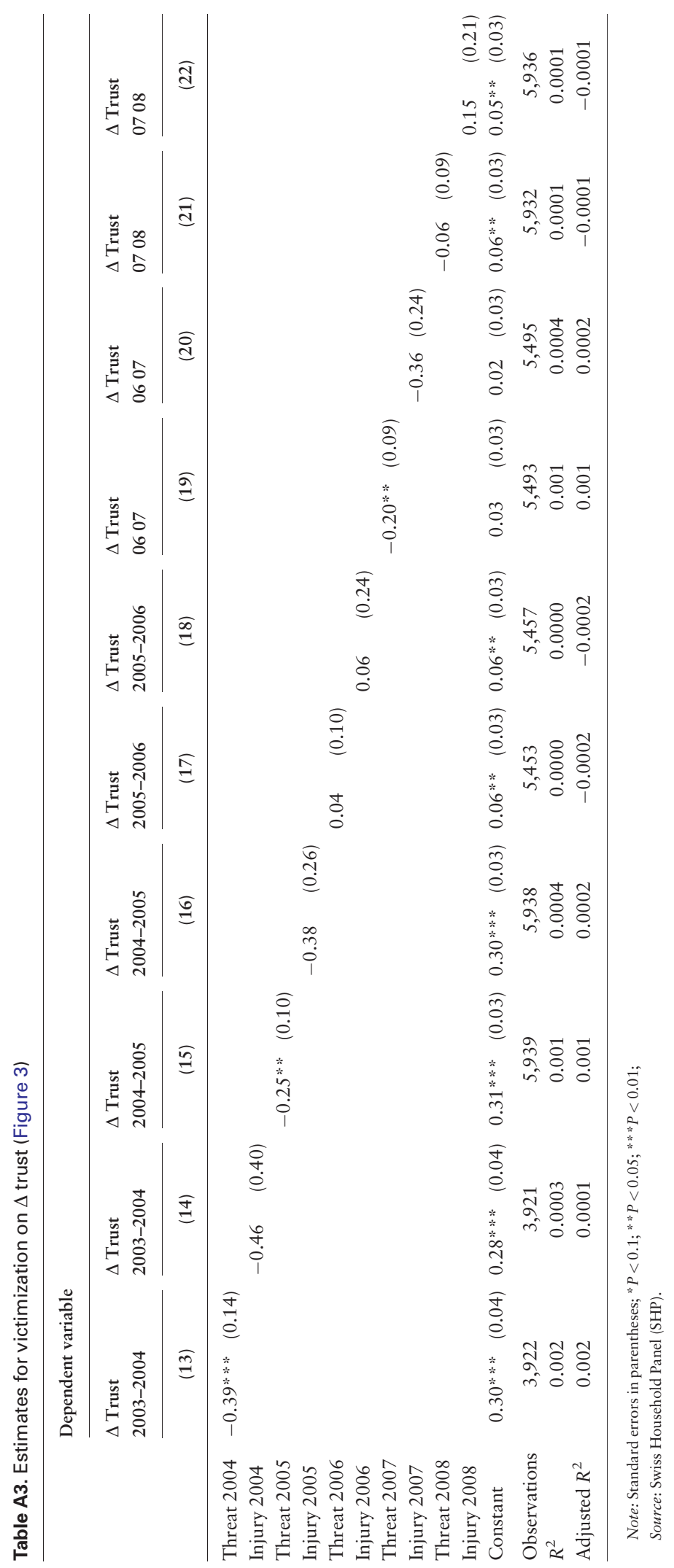



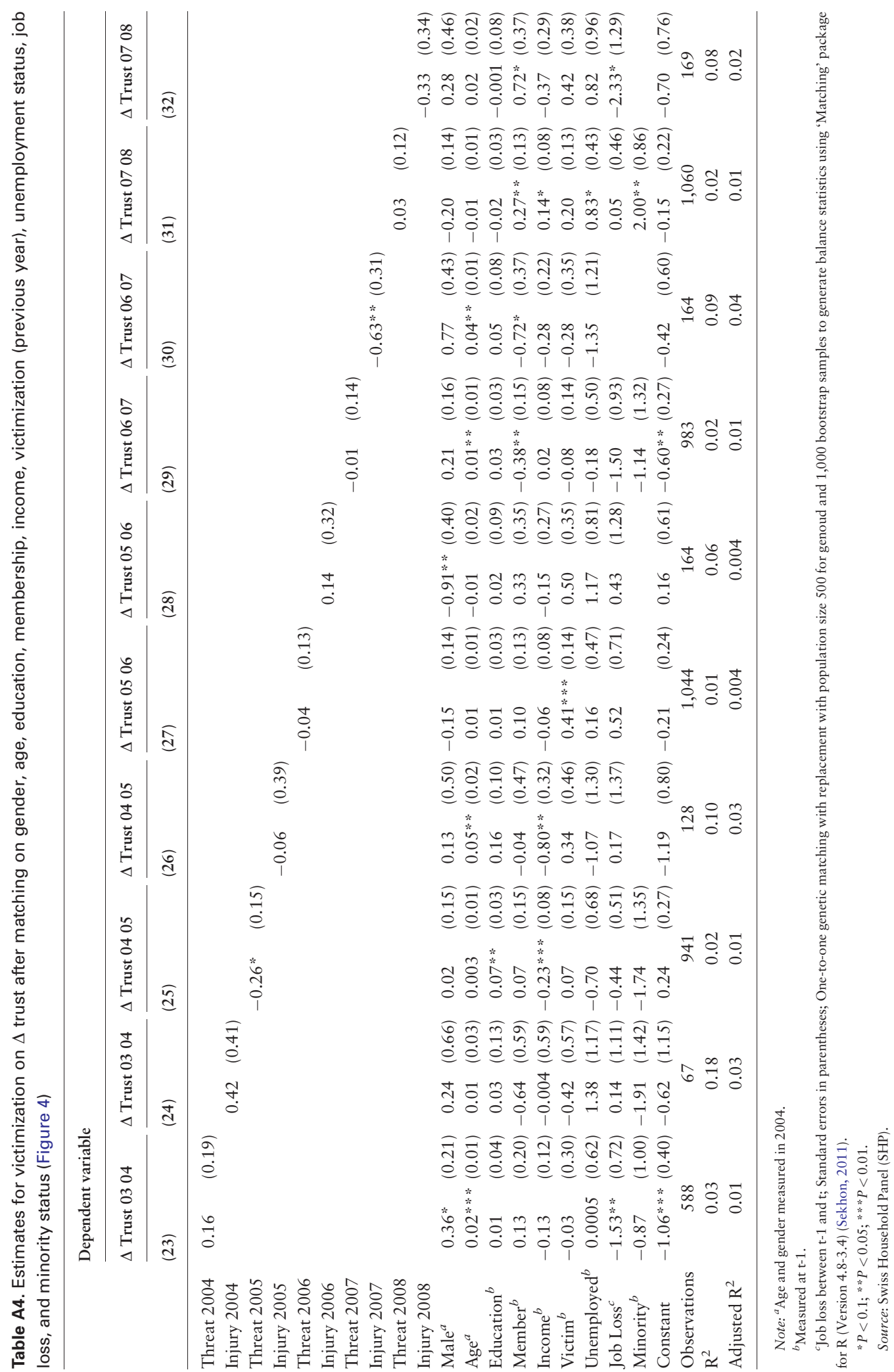
Table A5. Balance statistics for Model 23-Model 32 (Figure 4)

\begin{tabular}{|c|c|c|c|c|c|c|c|c|}
\hline Model: outcome/treatment & Variable & $\begin{array}{l}\text { Mean } \\
\text { difference } \\
\text { before }\end{array}$ & $\begin{array}{l}P \text { value } \\
\text { before }\end{array}$ & $\begin{array}{l}\text { Mean } \\
\text { difference } \\
\text { after }\end{array}$ & $\begin{array}{l}P \text { value } \\
\text { after }\end{array}$ & Orig. $N$ & $\begin{array}{l}\text { Orig. } \\
\text { treated } N\end{array}$ & $\begin{array}{l}N \text { matched } \\
\text { observation }\end{array}$ \\
\hline M 23: Trust 2003-2004 & Male & 0.09 & 0.02 & 0.00 & 1.00 & 2,558 & 209 & 379 \\
\hline \multirow[t]{8}{*}{ Threat 2004} & Age & -3.44 & 0.00 & -0.17 & 0.42 & 2,558 & 209 & 379 \\
\hline & Education 2003 & -0.15 & 0.47 & -0.04 & 0.48 & 2,558 & 209 & 379 \\
\hline & Member 2003 & -0.01 & 0.71 & 0.00 & 1.00 & 2,558 & 209 & 379 \\
\hline & Income 2003 & 0.05 & 0.50 & 0.02 & 0.45 & 2,558 & 209 & 379 \\
\hline & Victim 2003 & 0.12 & 0.00 & 0.00 & 1.00 & 2,558 & 209 & 379 \\
\hline & Unemployed 2003 & 0.01 & 0.24 & 0.00 & 0.32 & 2,558 & 209 & 379 \\
\hline & Job loss 2003-2004 & 0.01 & 0.36 & 0.00 & 1.00 & 2,558 & 209 & 379 \\
\hline & Minority 2003 & 0.01 & 0.44 & 0.00 & 1.00 & 2,558 & 209 & 379 \\
\hline M 24: Trust 2003-2004 & Male & 0.15 & 0.16 & 0.00 & 1.00 & 2,558 & 22 & 45 \\
\hline \multirow[t]{8}{*}{ Injury 2004} & Age & -10.64 & 0.00 & -0.21 & 0.74 & 2,558 & 22 & 45 \\
\hline & Education 2003 & -0.75 & 0.29 & -0.02 & 0.73 & 2,558 & 22 & 45 \\
\hline & Member 2003 & 0.05 & 0.64 & 0.00 & 1.00 & 2,558 & 22 & 45 \\
\hline & Income 2003 & -0.22 & 0.39 & 0.00 & 1.00 & 2,558 & 22 & 45 \\
\hline & Victim 2003 & 0.21 & 0.04 & 0.00 & 1.00 & 2,558 & 22 & 45 \\
\hline & Unemployed 2003 & 0.03 & 0.52 & 0.00 & 1.00 & 2,558 & 22 & 45 \\
\hline & Job loss 2003-2004 & 0.03 & 0.45 & 0.00 & 1.00 & 2,558 & 22 & 45 \\
\hline & Minority 2003 & 0.04 & 0.38 & 0.00 & 1.00 & 2,558 & 22 & 45 \\
\hline M 25: Trust 2004-2005 & Male & 0.06 & 0.04 & 0.00 & 1.00 & 3,867 & 337 & 604 \\
\hline \multirow[t]{8}{*}{ Threat 2005} & Age & -4.24 & 0.00 & 0.12 & 0.40 & 3,867 & 337 & 604 \\
\hline & Education 2004 & -0.27 & 0.12 & 0.04 & 0.45 & 3,867 & 337 & 604 \\
\hline & Member 2004 & 0.03 & 0.27 & 0.00 & 1.00 & 3,867 & 337 & 604 \\
\hline & Income 2004 & -0.06 & 0.38 & -0.01 & 0.53 & 3,867 & 337 & 604 \\
\hline & Victim 2004 & 0.42 & 0.00 & 0.00 & 1.00 & 3,867 & 337 & 604 \\
\hline & Unemployed 2004 & 0.00 & 0.97 & 0.00 & 1.00 & 3,867 & 337 & 604 \\
\hline & Job loss 2004-2005 & 0.01 & 0.24 & 0.00 & 1.00 & 3,867 & 337 & 604 \\
\hline & Minority 2004 & 0.00 & 0.69 & 0.00 & 1.00 & 3,867 & 337 & 604 \\
\hline M 26: Trust 2004-2005 & Male & 0.29 & 0.00 & 0.00 & 1.00 & 3,866 & 41 & 87 \\
\hline \multirow[t]{8}{*}{ Injury 2005} & Age & -14.11 & 0.00 & -0.11 & 0.64 & 3,866 & 41 & 87 \\
\hline & Education 2004 & -1.94 & 0.00 & -0.02 & 0.88 & 3,866 & 41 & 87 \\
\hline & Member 2004 & -0.12 & 0.13 & 0.00 & 1.00 & 3,866 & 41 & 87 \\
\hline & Income 2004 & -0.47 & 0.01 & 0.05 & 0.53 & 3,866 & 41 & 87 \\
\hline & Victim 2004 & 0.58 & 0.00 & 0.00 & 1.00 & 3,866 & 41 & 87 \\
\hline & Unemployed 2004 & 0.01 & 0.60 & 0.00 & 1.00 & 3,866 & 41 & 87 \\
\hline & Job loss 2004-2005 & 0.01 & 0.62 & 0.00 & 1.00 & 3,866 & 41 & 87 \\
\hline & Minority 2004 & 0.00 & 0.00 & 0.00 & 1.00 & 3,866 & 41 & 87 \\
\hline M 27: Trust 2005-2006 & Male & 0.08 & 0.01 & 0 & 1.00 & 3,601 & 365 & 679 \\
\hline \multirow[t]{8}{*}{ Threat 2006} & Age & -5.09 & 0.00 & 0 & 0.99 & 3,601 & 365 & 679 \\
\hline & Education 2005 & -0.47 & 0.01 & 0 & 1.00 & 3,601 & 365 & 679 \\
\hline & Member 2005 & 0.00 & 0.98 & 0 & 1.00 & 3,601 & 365 & 679 \\
\hline & Income 2005 & -0.15 & 0.02 & 0 & 1.00 & $3,, 601$ & 365 & 679 \\
\hline & Victim 2005 & 0.33 & 0.00 & 0 & 1.00 & 3,601 & 365 & 679 \\
\hline & Unemployed 2005 & 0.01 & 0.32 & 0 & 1.00 & 3,601 & 365 & 679 \\
\hline & Job loss 2005-2006 & 0.00 & 0.65 & 0 & 1.00 & 3,601 & 365 & 679 \\
\hline & Minority 2005 & -0.01 & 0.00 & 0 & 1.00 & 3,601 & 365 & 679 \\
\hline M 28: Trust 2005-2006 & Male & 0.24 & 0.00 & 0.00 & 1.00 & 3,604 & 46 & 118 \\
\hline \multirow[t]{3}{*}{ Injury 2006} & Age & -16.22 & 0.00 & -0.05 & 0.86 & 3,604 & 46 & 118 \\
\hline & Education 2005 & -2.23 & 0.00 & -0.02 & 0.86 & 3,604 & 46 & 118 \\
\hline & Member 2005 & -0.10 & 0.20 & 0.00 & 1.00 & 3,604 & 46 & 118 \\
\hline
\end{tabular}


Table A5. Continued

\begin{tabular}{|c|c|c|c|c|c|c|c|c|}
\hline Model: outcome/treatment & Variable & $\begin{array}{l}\text { Mean } \\
\text { difference } \\
\text { before }\end{array}$ & $\begin{array}{l}P \text { value } \\
\text { before }\end{array}$ & $\begin{array}{l}\text { Mean } \\
\text { difference } \\
\text { after }\end{array}$ & $\begin{array}{l}P \text { value } \\
\text { after }\end{array}$ & Orig. $N$ & $\begin{array}{l}\text { Orig. } \\
\text { treated } N\end{array}$ & $\begin{array}{l}\mathrm{N} \text { matched } \\
\text { observation }\end{array}$ \\
\hline & Income 2005 & -0.64 & 0.00 & 0.00 & 1.00 & 3,604 & 46 & 118 \\
\hline & Victim 2005 & 0.41 & 0.00 & 0.00 & 1.00 & 3,604 & 46 & 118 \\
\hline & Unemployed 2005 & 0.03 & 0.31 & 0.00 & 1.00 & 3,604 & 46 & 118 \\
\hline & Job loss 2005-2006 & 0.01 & 0.60 & 0.00 & 1.00 & 3,604 & 46 & 118 \\
\hline & Minority 2005 & -0.01 & 0.00 & 0.00 & 1.00 & 3,604 & 46 & 118 \\
\hline M 29: Trust 2006-2007 & Male & 0.11 & 0.00 & 0.00 & 0.86 & 3,502 & 342 & 641 \\
\hline \multirow[t]{8}{*}{ Threat 2007} & Age & -6.63 & 0.00 & -0.02 & 0.78 & 3,502 & 342 & 641 \\
\hline & Education 2006 & -0.68 & 0.00 & 0.01 & 0.76 & 3,502 & 342 & 641 \\
\hline & Member 2006 & 0.04 & 0.17 & 0.00 & 1.00 & 3,502 & 342 & 641 \\
\hline & Income 2006 & -0.18 & 0.01 & 0.00 & 0.86 & 3,502 & 342 & 641 \\
\hline & Victim 2006 & 0.38 & 0.00 & 0.00 & 1.00 & 3,502 & 342 & 641 \\
\hline & Unemployed 2006 & 0.01 & 0.32 & 0.00 & 1.00 & 3,502 & 342 & 641 \\
\hline & Job loss 2006-2007 & 0.00 & 0.86 & 0.00 & 1.00 & 3,502 & 342 & 641 \\
\hline & Minority 2006 & 0.00 & 0.22 & 0.00 & 1.00 & 3,502 & 342 & 641 \\
\hline M 30: Trust 2006-2007 & Male & 0.30 & 0.00 & 0.00 & 1.00 & 3,504 & 49 & 115 \\
\hline \multirow[t]{8}{*}{ Injury 2007} & Age & -13.92 & 0.00 & -0.06 & 0.90 & 3,504 & 49 & 115 \\
\hline & Education 2006 & -1.99 & 0.00 & 0.04 & 0.53 & 3,504 & 49 & 115 \\
\hline & Member 2006 & 0.09 & 0.18 & 0.00 & 1.00 & 3,504 & 49 & 115 \\
\hline & Income 2006 & -0.65 & 0.00 & 0.00 & 1.00 & 3,504 & 49 & 115 \\
\hline & Victim 2006 & 0.45 & 0.00 & 0.00 & 1.00 & 3,504 & 49 & 115 \\
\hline & Unemployed 2006 & 0.01 & 0.74 & 0.00 & 1.00 & 3,504 & 49 & 115 \\
\hline & Job loss 2006-2007 & -0.01 & 0.00 & 0.00 & 1.00 & 3,504 & 49 & 115 \\
\hline & Minority 2006 & -0.01 & 0.00 & 0.00 & 1.00 & 3,504 & 49 & 115 \\
\hline M 31: Trust 2007-2008 & Male & 0.10 & 0.00 & 0.00 & 1.00 & 3,480 & 372 & 688 \\
\hline \multirow[t]{8}{*}{ Threat 2008} & Age & -7.70 & 0.00 & 0.01 & 0.98 & 3,480 & 372 & 688 \\
\hline & Education 2007 & -0.81 & 0.00 & 0.00 & 1.00 & 3,480 & 372 & 688 \\
\hline & Member 2007 & 0.01 & 0.75 & 0.00 & 1.00 & 3,480 & 372 & 688 \\
\hline & Income 2007 & -0.20 & 0.00 & 0.00 & 1.00 & 3,480 & 372 & 688 \\
\hline & Victim 2007 & 0.38 & 0.00 & 0.00 & 1.00 & 3,480 & 372 & 688 \\
\hline & Unemployed 2007 & 0.01 & 0.10 & 0.00 & 1.00 & 3,480 & 372 & 688 \\
\hline & Job loss 2007-2008 & 0.01 & 0.06 & 0.00 & 1.00 & 3,480 & 372 & 688 \\
\hline & Minority 2007 & 0.00 & 0.73 & 0.00 & 1.00 & 3,480 & 372 & 688 \\
\hline M 32: Trust 2007-2008 & Male & 0.30 & 0.00 & 0.00 & 1.00 & 3,482 & 54 & 115 \\
\hline \multirow[t]{8}{*}{ Injury 2008} & Age & -9.79 & 0.00 & -0.08 & 0.62 & 3,482 & 54 & 115 \\
\hline & Education 2007 & -1.14 & 0.01 & -0.04 & 0.64 & 3,482 & 54 & 115 \\
\hline & Member 2007 & 0.04 & 0.54 & 0.00 & 1.00 & 3,482 & 54 & 115 \\
\hline & Income 2007 & -0.23 & 0.18 & 0.02 & 0.71 & 3,482 & 54 & 115 \\
\hline & Victim 2007 & 0.46 & 0.00 & 0.00 & 1.00 & 3,482 & 54 & 115 \\
\hline & Unemployed 2007 & 0.03 & 0.30 & 0.00 & 1.00 & 3,482 & 54 & 115 \\
\hline & Job loss 2007-2008 & 0.01 & 0.53 & 0.00 & 1.00 & 3,482 & 54 & 115 \\
\hline & Minority 2007 & -0.01 & 0.00 & 0.00 & 1.00 & 3,482 & 54 & 115 \\
\hline
\end{tabular}


Table A6. Estimates for victimization of high intensity on $\Delta$ trust after matching on gender, age, education, membership, incomes, victimization (previous year), unemployment status, job loss, and minority status (Figure 5)

\begin{tabular}{|c|c|c|c|c|c|c|c|c|c|c|}
\hline & \multicolumn{10}{|c|}{ Dependent variable } \\
\hline & \multirow{2}{*}{\multicolumn{2}{|c|}{$\frac{\Delta \text { Trust 2003-2004 }}{(33)}$}} & \multirow{2}{*}{\multicolumn{2}{|c|}{$\frac{\Delta \text { Trust 2004-2005 }}{(34)}$}} & \multirow{2}{*}{\multicolumn{2}{|c|}{$\frac{\Delta \text { Trust } 2005-2006}{(35)}$}} & \multirow{2}{*}{\multicolumn{2}{|c|}{$\frac{\Delta \text { Trust 2006-2007 }}{(36)}$}} & \multirow{2}{*}{\multicolumn{2}{|c|}{$\frac{\Delta \text { Trust } 2007-2008}{(37)}$}} \\
\hline & & & & & & & & & & \\
\hline Intense threat 2004 & -0.19 & $(0.55)$ & & & & & & & & \\
\hline Intense threat 2005 & & & -0.49 & $(0.44)$ & & & & & & \\
\hline Intense threat 2006 & & & & & -0.46 & $(0.42)$ & & & & \\
\hline Intense threat 2007 & & & & & & & -0.39 & $(0.43)$ & & \\
\hline Intense threat 2008 & & & & & & & & & -0.14 & $(0.46)$ \\
\hline Male $^{a}$ & $-1.42 *$ & $(0.75)$ & 0.63 & $(0.55)$ & 0.69 & $(0.55)$ & -0.50 & $(0.47)$ & $-1.45^{*}$ & $(0.82)$ \\
\hline $\operatorname{Age}^{a}$ & 0.01 & $(0.03)$ & 0.01 & $(0.03)$ & -0.01 & $(0.02)$ & -0.01 & $(0.02)$ & 0.01 & $(0.03)$ \\
\hline Education $^{b}$ & -0.17 & $(0.14)$ & -0.02 & $(0.09)$ & -0.05 & $(0.10)$ & 0.12 & $(0.09)$ & 0.04 & $(0.13)$ \\
\hline Member $^{b}$ & 1.12 & $(0.69)$ & -0.28 & $(0.47)$ & -0.54 & $(0.44)$ & -0.47 & $(0.48)$ & 0.66 & $(0.81)$ \\
\hline Income $^{b}$ & 0.50 & $(0.40)$ & $-0.54 * *$ & $(0.27)$ & -0.29 & $(0.54)$ & -0.04 & $(0.23)$ & 0.40 & $(0.38)$ \\
\hline Victim $^{b}$ & 0.35 & $(1.38)$ & -0.21 & $(0.51)$ & 0.83 & $(0.54)$ & -0.51 & $(0.46)$ & -0.21 & $(0.57)$ \\
\hline Unemployed $^{b}$ & 1.46 & $(1.80)$ & -0.36 & $(1.62)$ & 0.21 & $(0.88)$ & -0.98 & $(1.48)$ & & \\
\hline Job loss ${ }^{c}$ & & & 0.04 & $(1.04)$ & 1.23 & $(1.53)$ & & & -0.85 & $(1.27)$ \\
\hline Minority $^{b}$ & -0.51 & $(1.44)$ & & & & & & & 0.40 & $(1.30)$ \\
\hline Constant & -0.10 & $(1.59)$ & 1.37 & $(1.24)$ & 1.32 & $(1.04)$ & 0.21 & $(0.73)$ & -0.95 & $(1.26)$ \\
\hline Observations & \multicolumn{2}{|c|}{77} & \multicolumn{2}{|c|}{104} & \multicolumn{2}{|c|}{106} & \multicolumn{2}{|c|}{145} & \multicolumn{2}{|c|}{90} \\
\hline$R^{2}$ & \multicolumn{2}{|c|}{0.11} & \multicolumn{2}{|c|}{0.07} & \multicolumn{2}{|c|}{0.12} & \multicolumn{2}{|c|}{0.06} & \multicolumn{2}{|c|}{0.07} \\
\hline Adjusted $R^{2}$ & \multicolumn{2}{|c|}{-0.01} & \multicolumn{2}{|c|}{-0.02} & \multicolumn{2}{|c|}{0.03} & \multicolumn{2}{|c|}{0.01} & \multicolumn{2}{|c|}{-0.03} \\
\hline
\end{tabular}

Note: ${ }^{a}$ Age and gender measured in 2004

${ }^{b}$ Measured at $\mathrm{t}-1$.

'Job loss between $\mathrm{t}-1$ and $\mathrm{t}$; Standard errors in parentheses; One-to-one genetic matching with replacement with population size 500 for genoud and 1 , 000 bootstrap samples to generate balance statistics using 'Matching' package for R (Version 4.8-3.4) (Sekhon, 2011).

$* P<0.1 ; * P<0.05 ; * * P<0.01$.

Source: Swiss Household Panel (SHP). 
Table A7. Balance statistics for Model 33-Model 37 (Figure 5)

\begin{tabular}{|c|c|c|c|c|c|c|c|c|}
\hline Model: outcome/treatment & Variable & $\begin{array}{l}\text { Mean } \\
\text { difference } \\
\text { before }\end{array}$ & $\begin{array}{l}P \text { value } \\
\text { before }\end{array}$ & $\begin{array}{l}\text { Mean } \\
\text { difference } \\
\text { after }\end{array}$ & $\begin{array}{l}P \text { value } \\
\text { after }\end{array}$ & $\begin{array}{l}\text { Orig. } \\
N\end{array}$ & $\begin{array}{l}\text { Orig. } \\
\text { treated } N\end{array}$ & $\begin{array}{l}N \text { matched } \\
\text { obs. }\end{array}$ \\
\hline M 33: Trust 2003-2004 & Male & -0.18 & 0.05 & 0.00 & 1.00 & 2,379 & 30 & 47 \\
\hline \multirow[t]{8}{*}{ Intense threat 2004} & Age & 0.55 & 0.80 & -0.10 & 0.83 & 2,379 & 30 & 47 \\
\hline & Education 2003 & -0.06 & 0.91 & -0.03 & 0.82 & 2,379 & 30 & 47 \\
\hline & Member 2003 & -0.15 & 0.11 & 0.00 & 1.00 & 2,379 & 30 & 47 \\
\hline & Income 2003 & -0.08 & 0.68 & 0.00 & 1.00 & 2,379 & 30 & 47 \\
\hline & Victim 2003 & 0.05 & 0.27 & 0.00 & 1.00 & 2,379 & 30 & 47 \\
\hline & Unemployed 2003 & 0.02 & 0.59 & 0.00 & 1.00 & 2,379 & 30 & 47 \\
\hline & Job loss 2003-2004 & -0.01 & 0.00 & 0.00 & 1.00 & 2,379 & 30 & 47 \\
\hline & Minority 2003 & 0.06 & 0.19 & 0.03 & 0.32 & 2,379 & 30 & 47 \\
\hline M 34: Trust 2004-2005 & Male & -0.14 & 0.06 & 0.00 & 1.00 & 3,574 & 44 & 60 \\
\hline \multirow[t]{8}{*}{ Intense threat 2005} & Age & 1.55 & 0.33 & 0.02 & 0.97 & 3,574 & 44 & 60 \\
\hline & Education 2004 & 0.29 & 0.52 & 0.00 & 1.00 & 3,574 & 44 & 60 \\
\hline & Member 2004 & -0.04 & 0.65 & 0.02 & 0.81 & 3,574 & 44 & 60 \\
\hline & Income 2004 & 0.17 & 0.31 & 0.02 & 0.80 & 3,574 & 44 & 60 \\
\hline & Victim 2004 & 0.45 & 0.00 & 0.00 & 1.00 & 3,574 & 44 & 60 \\
\hline & Unemployed 2004 & 0.01 & 0.63 & 0.00 & 1.00 & 3,574 & 44 & 60 \\
\hline & Job loss 2004-2005 & 0.06 & 0.15 & 0.00 & 1.00 & 3,574 & 44 & 60 \\
\hline & Minority 2004 & 0.00 & 0.00 & 0.00 & 1.00 & 3,574 & 44 & 60 \\
\hline M 35: Trust 2005-2006 & Male & -0.17 & 0.02 & 0.00 & 1.00 & 3,279 & 43 & 63 \\
\hline \multirow[t]{8}{*}{ Intense threat 2006} & Age & 1.68 & 0.39 & -0.12 & 0.71 & 3,279 & 43 & 63 \\
\hline & Education 2005 & -0.27 & 0.49 & -0.09 & 0.73 & 3,279 & 43 & 63 \\
\hline & Member 2005 & -0.04 & 0.62 & 0.00 & 1.00 & 3,279 & 43 & 63 \\
\hline & Income 2005 & -0.17 & 0.31 & 0.00 & 1.00 & 3,279 & 43 & 63 \\
\hline & Victim 2005 & 0.26 & 0.00 & 0.00 & 1.00 & 3,279 & 43 & 63 \\
\hline & Unemployed 2005 & 0.06 & 0.15 & 0.00 & 1.00 & 3,279 & 43 & 63 \\
\hline & Job loss 2005-2006 & 0.01 & 0.59 & 0.00 & 1.00 & 3,279 & 43 & 63 \\
\hline & Minority 2005 & -0.01 & 0.00 & 0.00 & 1.00 & 3,279 & 43 & 63 \\
\hline M 36: Trust 2006-2007 & Male & 0.01 & 0.86 & 0.00 & 1.00 & 3,199 & 39 & 106 \\
\hline \multirow[t]{8}{*}{ Intense threat 2007} & Age & -4.72 & 0.07 & -0.19 & 0.88 & 3,199 & 39 & 106 \\
\hline & Education 2006 & -0.40 & 0.45 & -0.03 & 0.75 & 3,199 & 39 & 106 \\
\hline & Member 2006 & -0.07 & 0.42 & 0.00 & 1.00 & 3,199 & 39 & 106 \\
\hline & Income 2006 & -0.41 & 0.03 & 0.00 & 1.00 & 3,199 & 39 & 106 \\
\hline & Victim 2006 & 0.26 & 0.00 & 0.00 & 1.00 & 3,199 & 39 & 106 \\
\hline & Unemployed 2006 & 0.01 & 0.62 & 0.00 & 1.00 & 3,199 & 39 & 106 \\
\hline & Job loss 2006-2007 & -0.01 & 0.00 & 0.00 & 1.00 & 3,199 & 39 & 106 \\
\hline & Minority 2006 & -0.01 & 0.00 & 0.00 & 1.00 & 3,199 & 39 & 106 \\
\hline M 37: Trust 2007-2008 & Male & -0.19 & 0.04 & 0.00 & 1.00 & 3,136 & 28 & 62 \\
\hline \multirow[t]{8}{*}{ Intense threat 2008} & Age & 2.18 & 0.41 & 0.02 & 0.95 & 3,136 & 28 & 62 \\
\hline & Education 2007 & -1.13 & 0.05 & -0.03 & 0.84 & 3,136 & 28 & 62 \\
\hline & Member 2007 & -0.27 & 0.01 & 0.00 & 1.00 & 3,136 & 28 & 62 \\
\hline & Income 2007 & -0.31 & 0.13 & 0.00 & 1.00 & 3,136 & 28 & 62 \\
\hline & Victim 2007 & 0.26 & 0.01 & 0.00 & 1.00 & 3,136 & 28 & 62 \\
\hline & Unemployed 2007 & -0.01 & 0.00 & 0.00 & 1.00 & 3,136 & 28 & 62 \\
\hline & Job loss 2007-2008 & 0.03 & 0.40 & 0.00 & 1.00 & 3,136 & 28 & 62 \\
\hline & Minority 2007 & 0.03 & 0.42 & 0.00 & 1.00 & 3,136 & 28 & 62 \\
\hline
\end{tabular}

